Ecología Aplicada, 2(1), 2003

ISSN 1726-2216

Depósito legal 2002-5474

\title{
VIABILIDAD DE CEPAS DE RIZOBIOS EN INOCULANTES BASADOS EN SOPORTES NO ESTÉRILES
}

Gisella Matos Cuzcano ${ }^{1}$ y Doris Zúñiga Dávila ${ }^{1}$

\begin{abstract}
Resumen
Se evaluó la supervivencia de las cepas PLL113 de Bradyrhizobium sp. y PLC213 de Rhizobium sp. en dos inoculantes elaborados en base a turba y una mezcla de suelo-compost no estériles almacenados a $4^{\circ} \mathrm{C}$ durante seis meses. Las poblaciones de ambas cepas disminuyeron durante el almacenamiento en ambos tipos de inoculantes, sin embargo la turba permitió una mejor supervivencia. Se registraron evidencias de antagonismos o competencia entre las bacterias mesófilas totales (BMT) y mohos contaminantes. Así mismo se observaron correlaciones negativas entre las poblaciones de rizobios y el resto de microorganismos, lo que indica su pobre competitividad frente a los contaminantes. La calidad microbiológica comprendida como la concentración mínima de rizobios por gramo de los inoculantes fue satisfactoria durante las siete primeras semanas de almacenamiento.
\end{abstract}

Palabras claves: Rhizobium, compost, turba, nódulos.

\section{Abstract}

The survival of Bradyrhizobium sp. PLL113 and Rhizobium sp. PLC213 in soil-compost and peat based unsterile inoculants stored at $4{ }^{\circ} \mathrm{C}$ during 6 months was evaluated. The populations of both strains decreased during storage in both type of inoculants, although better survival was observed in peat. Evidence of antagonisms or competition between total contaminant bacteria and moulds was registered. In addition, negative correlations were observed between rhizobial populations and the rest of microorganisms, which indicated its poor competitiveness against contaminants. The inoculants microbiological quality was satisfactory during the first seven weeks of storage.

Key words: Rhizobium, compost, peat, nodules.

\section{Introducción}

Las leguminosas tienen la capacidad de establecer una asociación simbiótica con bacterias de la familia Rhizobiaceae, comúnmente conocidas como rizobios. Estas bacterias inducen en la planta la formación de estructuras especializadas, denominadas nódulos, en donde se alojan como simbiontes intracelulares y fijan nitrógeno atmosférico que es utilizado por la planta.

Para obtener un buen rendimiento en el cultivo de leguminosas es necesaria la utilización de fertilizantes nitrogenados, los cuales elevan los costos de producción afectando la economía de los productores y consumidores. Una alternativa a este problema es la utilización de inoculantes bacterianos que porten rizobios viables y seleccionados por su infectividad y efectividad simbióticas (Hamdi, 1985).

Actualmente, los inoculantes en base a soportes sólidos son los más ampliamente difundidos. Se utilizan varios tipos de soportes como turba (Smith, 1992), carbón mineral (Paczkowski \& Berryhill, 1979), mezclas suelo-vermicompost (Benedetti et al., 1991), suelo-compost (Ormeño-Orrillo \& ZúñigaDávila, 1999a), suelo-carbon vegetal (Beck et al., 1993) y suelo-paja de arroz (Pramakik \& Iswaran,
1973). En muchos casos se recurre a la esterilización de estos soportes en autoclave (Ormeño-Orrillo \& Zúñiga-Dávila, 1999b) o por irradiación gamma (Strijdom \& Jansen van Rensburg, 1981). Sin embargo esta práctica eleva los costos de producción de los inoculantes y por otro lado la esterilización por calor, puede conllevar a la liberación o producción de compuestos tóxicos para los rizobios.

La fabricación del inoculante debe estar respaldado por un estricto control que asegure la calidad del producto, el control del inoculante se realiza en distintas fases del proceso parra comprobar las características cualitativas y cuantitativas de la población rizobiana del inoculante. Según la legislación brazileña el fabricante de inoculantes debe cumplir con los siguientes requisitos: empleo de cepas recomendadas por organismos de investigación y garantía mínima de que el producto contiene 10 milones de rizobios por gramo.

El objetivo del presente trabajo fue evaluar la viabilidad de cepas de rizobios durante un almacenamiento prolongado en dos inoculantes no estériles elaborados en base a turba y una mezcla de suelo-compost.

\footnotetext{
${ }^{1}$ Laboratorio de Ecología Microbiana y Biotecnología "Marino Tabusso", Universidad Nacional Agraria La Molina. Apartado Postal 456, Lima 100, Perú. Correo electrónico : gmc@lamolina.edu.pe / dzuniga@lamolina.edu.pe
} 


\section{Materiales y métodos \\ Microorganismos y condiciones de cultivo}

Se utilizaron las cepas PLL113 de Bradyrhizobium sp. y PLC213 de Rhizobium sp. aisladas de nódulos de pallar (Phaseolus lunatus L.) (Matos-Cuzcano et al., 1998) y pertenecientes a la colección del Laboratorio de Ecología Microbiana y Biotecnología "Marino Tabusso" de la Universidad Nacional Agraria La Molina (UNALM). Los cultivos stock fueron mantenidos a $4^{\circ} \mathrm{C}$ en tubos con agar extracto de levadura manitol (LMA) (Beck et al., 1993) en plano inclinado. Las cepas fueron sembradas independientemente en 4 frascos Roux que contenían $25 \mathrm{~mL}$ de LMA en plano inclinado. Los cultivos se incubaron a $28^{\circ} \mathrm{C}$ por tres y siete días para la cepa de Rhizobium y Bradyrhizobium, respectivamente. Los inóculos se obtuvieron agregando $20 \mathrm{~mL}$ de solución salina $(0,85 \%)$ estéril a los frascos y realizando una suspensión homogénea de las bacterias.

\section{Elaboración de los soportes}

Los soportes se elaboraron utilizando suelo recolectado en el campus de la UNALM, compost adquirido en el Programa de Leguminosas - UNALM y turba donada por el Intituto Nacional de Investigación Agraria (INIA). El suelo y el compost se tamizaron a través de una malla de $0,16 \mathrm{~mm}$. Los tres materiales se colocaron independientemente en bolsas de tela y fueron pasteurizados a vapor fluente por una hora en tres días consecutivos incubándolos a $37{ }^{\circ} \mathrm{C}$ entre cada tratamiento para permitir el crecimiento de la microflora sobreviviente (Alder \& Simpson, 1982). Luego del tercer tratamiento se incubaron nuevamente a $37{ }^{\circ} \mathrm{C}$ para disminuir su humedad. El compost y el suelo se mezclaron en la proporción de 2:3 (p:p) y la mezcla resultante se empaquetó en bolsas de polietileno (200 g/bolsa). La turba también fue dispensada en bolsas en igual cantidad.

\section{Elaboración de los inoculantes}

Las bolsas con los soportes pasteurizados fueron impregnadas en condiciones asépticas con $40 \mathrm{~mL}$ de las suspensiones bacterianas, dejando como controles una bolsa de cada soporte sin inocular. Cada inoculante fue posteriormente separado en bolsas de $100 \mathrm{~g}$ cada una, obteniéndose 2 bolsas de inoculante de cada tipo para ambas cepas. Luego de un periodo de maduración de 24 h (Materon \& Weaver, 1985), los inoculantes se almacenaron en refrigeración a $4^{\circ} \mathrm{C}$.

\section{Evaluaciones}

Luego de la maduración y a los 47, 76, 96 y 176 días de almacenamiento se evaluaron las poblaciones de rizobios, bacterias mesófilas totales (BMT), mohos y levaduras determinando el número de unidades formadoras de colonia (UFC) por el método de dilución decimal y recuento en placa (Speidel \& Wollum, 1980). Los medios de cultivo utilizados fueron LMA suplementado con Rojo Congo e incubado a $28^{\circ} \mathrm{C}$, agar Plate Count incubado a $28^{\circ} \mathrm{C}$ y agar Sabouraud incubado a temperatura ambiente para rizobios, BMT, y mohos y levaduras, respectivamente. Para el análisis, los datos se expresaron en base a peso seco y se transformaron a $\log _{10} \mathrm{UFC} / \mathrm{g}$.

\section{Inoculación en plantas}

Se agregó $1 \mathrm{~g}$ de los inoculantes almacenados por 176 días a plantas de pallar cultivadas en tubos de ensayo $(25 \times 150 \mathrm{~mm})$ con agar Sandman (CIAT, 1988) en plano inclinado. Las plantas se mantuvieron en una cámara de crecimiento con fotoperíodo de $12 \mathrm{~h}$ y se regaron con solución Sandman diluida 1:4 (v:v) cada dos o tres días. Al control con nitrógeno se le agregó 103,9 mg de urea por litro de solución Sandman. A los 30 d se finalizó el ensayo y se determinaron el número de nódulos y peso seco de la parte aérea.

\section{Resultados y discusión}

La población inicial de rizobios presente en los inoculantes fue de $10^{10}$ a $10^{11} \mathrm{UFC} / \mathrm{g}$ para la cepa PLC213 y de $10^{9}$ a $10^{10} \mathrm{UFC} / g$ para la cepa PLL113. Al evaluar la población a través del tiempo se observó un descenso paulatino de ambas cepas de ambos inoculantes (Tabla 1, Figuras 1 y 2). La viabilidad de las dos cepas utilizadas fue mayor en el soporte turba en comparación al soporte suelo-compost hasta los 176 días. Así también, se observó que la cepa PLC213 sobrevivió mejor que la cepa PLL113 en el soporte suelo-compost, mientras que lo contrario sucedió en el soporte turba.

La pasteurización y secado aplicado inicialmente a los soportes redujo la población inicial de BMT hasta $10^{5} \mathrm{UFC} / \mathrm{g}$ y a $10^{2} \mathrm{UFC} / \mathrm{g}$ para mohos. La mayor proporción de microorganismos detectados en el medio Plate Count fueron bacilos esporulados Gram positivos lo que cabria esperarse luego del tratamiento térmico (Alder \& Simpson, 1982), mientras que en agar Sabouraud sólo se obtuvo desarrollo de mohos filamentosos mas no así de levaduras. Las poblaciones de ambos grupos microbianos aumentaron durante los primeros 47 días de almacenamiento en ambos soportes. A los 76 días se observó una tendencia hacia el aumento de las poblaciones de BMT y a una disminución de los mohos presentes. Por el contrario, a los 96 días las BMT disminuyeron o se mantuvieron estables mientras que las poblaciones de mohos aumentaron.

Al final del experimento (176 días) todas las poblaciones disminuyeron (Fig. 3 y 4). Vistos en conjunto, estos resultados indicarían una competencia o antagonismo entre ambos grupos microbianos. El incremento inicial de ambas poblaciones se explicaría por la abundante presencia de nutrientes en ambos 
soportes que permitirían su desarrollo. Al disminuir la concentración de estos nutrientes (76 días), las bacterias tendrían una ventaja sobre los mohos por su mayor velocidad de crecimiento. Sin embargo al agotarse los nutrientes iniciales (96 días) los mohos podrían competir mejor por su capacidad de degradar residuos celulósicos y sustancias orgánicas complejas.

El agotamiento de los nutrientes y/o la acumulación de catabolitos tóxicos explicarían la disminución de ambas poblaciones a los 176 días.

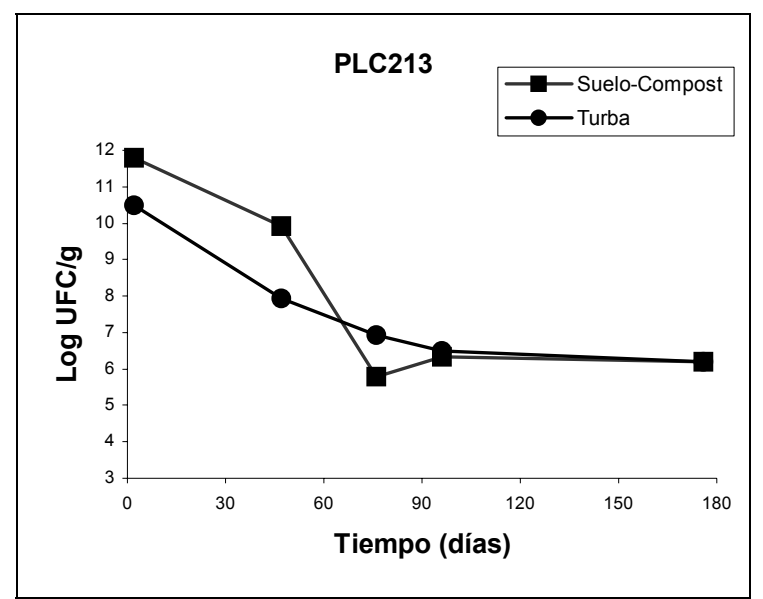

Figura 1. Viabilidad de la cepa PLC213 de Rhizobium sp. en inoculantes no estériles a base de suelo-compost y turba almacenados a $4^{\circ} \mathrm{C}$.

Tabla 1. Viabilidad de las cepas PLC213 de Rhizobium sp. y PLL113 de Bradyrhizobium sp. en inoculantes no estériles a base de suelo-compost (SC) y turba (T) almacenados a $4{ }^{\circ} \mathrm{C}$.

\begin{tabular}{cccccc}
\hline & \multicolumn{4}{c}{${\text { Viabilidad }(\%)^{a}}^{a}$} \\
\cline { 2 - 3 } \cline { 5 - 6 } Tiempo & \multicolumn{2}{c}{ PLC213 } & & \multicolumn{2}{c}{ PLL113 } \\
\cline { 2 - 3 } \cline { 5 - 6 } & S-C & T & & S-C & T \\
\hline 2 & 100 & 100 & & 100 & 100 \\
47 & 84,1 & 75,6 & & 63,6 & 93,2 \\
76 & 49,0 & 66,1 & & 47,7 & 74,9 \\
96 & 53,6 & 61,9 & & 41,6 & 63,5 \\
176 & 52,4 & 59,1 & & 35,1 & 63,8 \\
\hline
\end{tabular}

${ }^{a}$ Porcentaje de sobrevivencia en base a $\log _{10}$ de UFC/g

Las interacciones descritas anteriormente también se manifestaron entre los rizobios y las poblaciones de BMT y mohos. Sin tomar en cuenta la ultima evaluación en la cual todas poblaciones disminuyeron, se obtuvieron correlaciones negativas entre las poblaciones de rizobios, BMT y mohos (Tabla 2). El caso extremo lo presentó la interacción entre cepa PLL113 de Bradyrhizobium sp. y las BMT en el soporte suelo-compost $(r=-0,93)$. Esta cepa fue la que presentó la menor supervivencia en ese soporte, en el cual también se cuantificaron las mayores poblaciones de BMT y estas se mantuvieron elevadas por más tiempo. En comparación, Ormeño-Orrillo \&

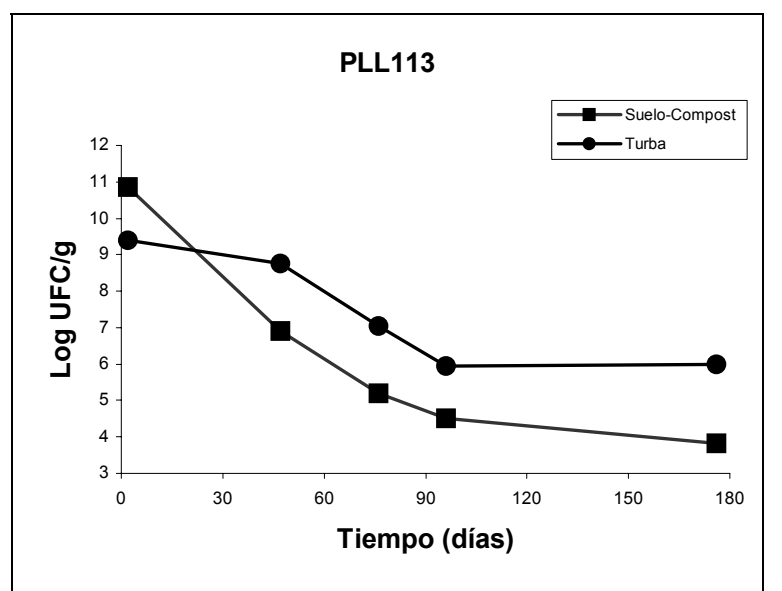

Figura 2. Viabilidad de la cepa PLL113 de Bradyrhizobium $\mathrm{sp}$. en inoculantes no estériles a base de suelo-compost y turba almacenados a $4^{\circ} \mathrm{C}$.

Zúñiga-Dávila (1999a) observaron una mejor supervivencia de la cepa PLL113 en un soporte similar pero esterilizado. Los resultados obtenidos indican que los rizobios son pobres competidores frente al resto de la microflora presente en los soportes utilizados para elaborar inoculantes. Si bien el uso de soportes estériles conlleva a mayores costos de producción de los inoculantes, su uso se justifica ya que permite eliminar la competencia y/o antagonismo de hongos y otras bacterias, y la predación por protozoarios (Van Schreven, 1970).

Tabla 2. Coeficientes de correlación entre las poblaciones de rizobios y de BMT y mohos en dos inoculantes a base de suelo-compost (S-C) y turba (T).

\begin{tabular}{lccccc}
\hline & \multicolumn{2}{c}{ BMT } & & \multicolumn{2}{c}{ Mohos } \\
\cline { 2 - 3 } \cline { 5 - 6 } Rizobio & S-C & T & & S-C & T \\
\hline PLL113 & $-0,93$ & $-0,62$ & & $-0,28$ & $-0,52$ \\
PLC213 & $-0,22$ & $-0,20$ & & $-0,37$ & $-0,70$ \\
\hline
\end{tabular}

A los 176 días de almacenamiento se evaluaron la infectividad y efectividad de los inoculantes en plántulas de pallar. A pesar de mantener una población mayor a $10^{6} \mathrm{UFC} / \mathrm{g}$, la cepa PLC213 de Rhizobium sp. no indujo la formación de nódulos. Las plantas tratadas con los inoculantes con la cepa PLL113 de Bradyrhizobium sp. a base de suelocompost y turba produjeron un promedio de 51,3 y 130,4 nódulos/planta, respectivamente. Así mismo, el peso seco de estas plantas fue mayor que el de los controles no inoculados (con y sin nitrógeno). Estos resultados pueden explicarse por la naturaleza de los determinantes genéticos que contienen la información para el proceso simbiótico en cada una de las cepas. En el género Rhizobium los genes para la nodulación y fijación de nitrógeno se encuentran en sus plásmidos, mientras que en el género Bradyrhizobium, dichos genes están integrados en su 
cromosoma (Jordan, 1984). Al ser el plásmido un elemento genético accesorio, es probable que la cepa de Rhizobium PLC213 lo haya perdido durante el periodo de almacenamiento. Por el contrario, la cepa de Bradyrhizobium PLL113 mantuvo su capacidad infectiva y efectiva debido a la estabilidad inherente de poseer esta información en el cromosoma.

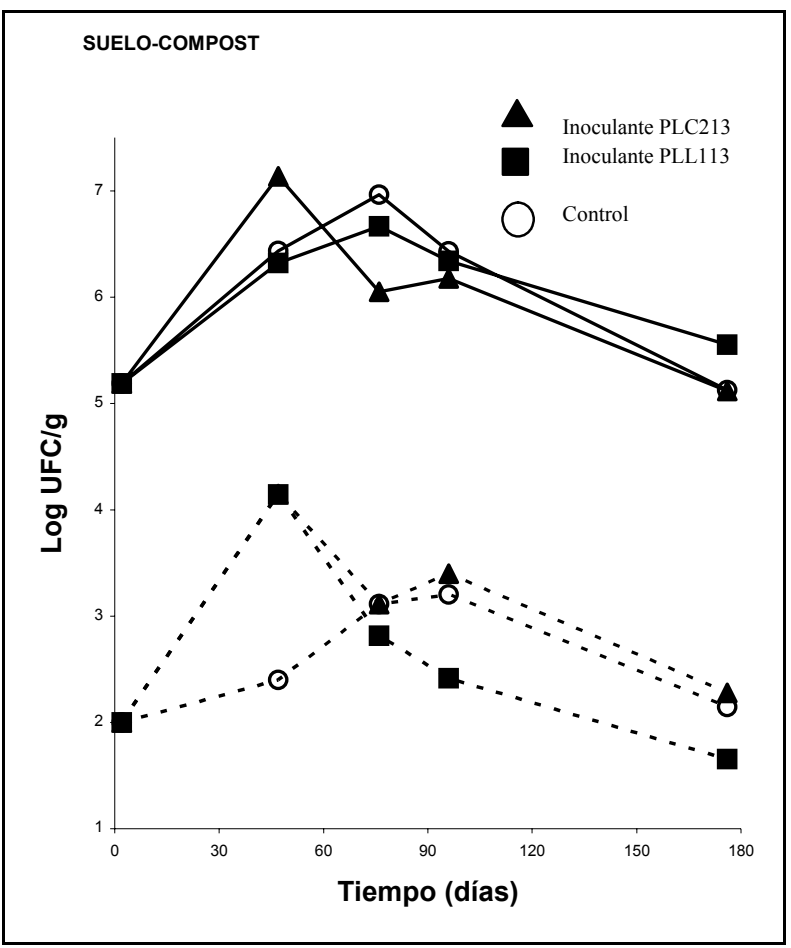

Figura 3. Variación de las poblaciones de BMT (líneas contiguas) y mohos (lineas punteadas) en los inoculantes a base de suelo-compost.

Los estándares de calidad para el número de rizobios que debe tener un inoculante sólido varían de acuerdo a las legislaciones vigentes en cada país entre $10^{7}$ y $10^{9} \mathrm{UFC} / \mathrm{g}$ (Boonkerd, 1991; RodríguezNavarro et al., 1991; Thompson, 1996). Los inoculantes analizados en este estudio se adecuaron a estos estándares durante los primeros 47 días de almacenamiento. Esto representa un periodo de vida útil corto en comparación con otros tipos de materiales como la turba (Somasegaran, 1985) o el carbón mineral (Paczkowski \& Berryhill, 1979). Fue interesante observar que la turba utilizada no resultó ser un buen soporte teniendo en cuenta que se han reportado periodos de vida útil de hasta 6 meses para inoculantes basados en este material. Sin embargo, turbas de mala calidad pueden acortar bastante este periodo útil (Pramakik \& Iswaran, 1973; Sparrow \& Ham, 1983).

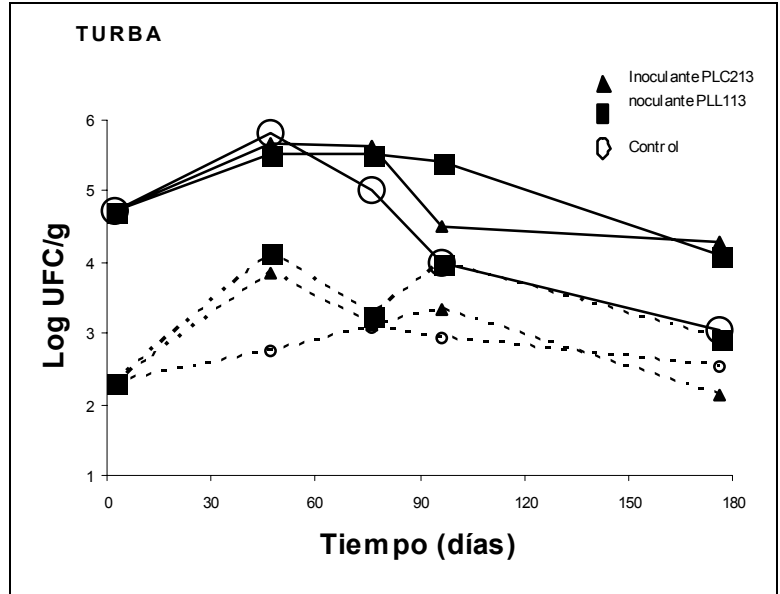

Figura 4. Variación en las poblaciones de BMT (líneas continuas) y mohos (lineas punteadas) en los inoculantes a base de turba.

\section{Conclusiones}

1. La turba permitió una mejor supervivencia de los rhizobios en comparación a la mezcla suelo-compost.

2. En relación a estándares internacionales, la calidad microbiológica (según la legislación brasileña la concentración mínima de rizobios debe ser 100 millones por gramo ) de los inoculantes fue satisfactoria durante las primeras 7 semanas de almacenamiento.

3. Se recomienda la utilización de soporte estériles pues los contaminantes pueden inhibir la población rhizobiana presente en el inoculante.

\section{Literatura citada}

Alder V.G. \& Simpson R.A. 1982. Sterilization and disinfection by heat methods. pp. 433-453. En: Principles and Practice of Disinfection, Preservation and Sterilization. A.D. Russell, W.B. Hugo y G.A.J. Ayliffe (Eds.). Blackwell Scientific Publications. Oxford.

Beck D.P., Materon L.A. \& Afandi F. 1993. Practical Rhizobium-Legume Technology Manual. Technical Manual $N^{\circ} 19$. International Center for Agricultural Research in the Dry Areas (ICARDA). Alepo.

Benedetti E., Zúñiga D. \& Carbajal N. 1991. Viabilidad y efectividad de diez inoculantes de Rhizobium almacenados durante seis meses a $4^{\circ} \mathrm{C}$. p. 113. En: Segunda Reunión de Expertos en Leguminosas de Grano de la Zona Andina. Cali.

Boonkerd N. 1991. Inoculant quality control and standards in Thailand. pp. 121-130. En: Report on the Expert consultation on legume inoculant production and quality control. J.A. Thompson (ed.). Roma.

CIAT (Centro Internacional de Agricultura Tropical). 1988. Simbiosis Leguminosa-Rizobio. Manual de Métodos de Evaluación, Selección y Manejo Agronómico. Cali. 
Hamdi Y.A. 1985. La fijación del nitrógeno en la explotación de los suelos. Boletín de suelos de la FAO N ${ }^{\circ}$ 49. FAO. Roma.

Jordan D.C. 1984. Family III. Rhizobiaceae Conn 1938. pp. 234-256. En: Bergey's Manual of Systematic Bacteriology, vol. I. N.R. Krieg and J.G. Holt (Eds.). The Williams \& Wilkins Co. Baltimore.

Materon L.A. \& Weaver R.W. 1985. Inoculant maturity influences survival of rhizobia on seed. Appl. Environ. Microbiol. 49: 465-467.

Matos-Cuzcano G., Ormeño-Orrillo E. \& ZúñigaDávila D. 1998. Diversidad de los rizobios que nodulan el cultivo de pallar (Phaseolus lunatus L.) en la costa central del Perú. Ecología. 1: 42-46.

Ormeño-Orrillo E. \& Zúñiga-Dávila D. 1999a. Supervivencia y características simbióticas de Bradyrhizobium sp. inoculado en una mezcla de suelo y compost. Biota. 17(99): 41-49.

Ormeño-Orrillo E. \& Zúñiga-Dávila D. 1999b. Optimización del tiempo de esterilización de soportes basados en suelo y compost en la producción de inoculantes para leguminosas. Revista Peruana de Biología. 6(2): 181-184.

Paczkowski M.W. \& Berryhill D.L. 1979. Survival of Rhizobium phaseoli in coal-based legume inoculants. Appl. Environ. Microbiol. 38: 612-615.

Pramanik M. \& Iswaran V. 1973. Survival of Rhizobium japonicum in various carriers. Zbl. Bakt. Abt. II. 128: 232-239.

Rodríguez-Navarro D.N., Temprano F. \&. Orive R. 1991. Survival of Rhizobium sp. (Hedysarum coronarium L.) on peat-based inoculants and inoculated seeds. Soil Biol. Biochem. 23: 375-379.

Smith R.S. 1992. Legume inoculant formulation and application. Can. J. Microbiol. 38: 485-492.

Somasegaran P. 1985. Inoculant production with diluted liquid cultures of Rhizobium sp. and autoclaved peat: evaluation of diluents, Rhizobium sp., peats, sterility requirements, storage, and plant effectiveness. Appl. Environ. Microbiol. 50: 398405.

Sparrow S.D. \& Ham G.E. 1983. Survival or Rhizobium phaseoli in six carriers materials. Agron. J. 75: 181184.

Speidel K.L. \& Wollum A.G. 1980. Evaluation of leguminous inoculant quality. Technical Bulletin $\mathrm{N}^{\circ}$ 266. North Caroline Agricultural Research Service. Raleigh.

Strijdom B.W. \& Jansen Van Rensburg H. 1981. Effect of steam sterilization and gamma irradiation of peat on quality of Rhizobium inoculants. Appl. Environ. Microbiol. 41: 1344-1347.

Thompson J.A. 1996. ¿Estamos haciendo el mejor uso de la tecnología de inoculantes?. pp. 417-436. En: XVIII Reunión Latinoamericana de Rhizobiología. J. Pijnenborg, D. Ruíz y W. Siles (Eds.). Santa Cruz de la Sierra.

Van Schreven D.A. 1970. Some factors affecting growth and survival of Rhizobium sp. in soil-peat cultures. Plant Soil. 32: 113-130. 